\title{
The Impact of Task Structure and Negotiation Sequence on Distributed Requirements Negotiation Activity, Conflict, and Satisfaction
}

\author{
Bartel Van de Walle ${ }^{1}$, Catherine Campbell ${ }^{2}$, and Fadi P. Deek ${ }^{2}$ \\ ${ }^{1}$ Department of Information Systems and Management, Tilburg University, The Netherlands \\ ${ }^{2}$ College of Computing Sciences, New Jersey Institute of Technology, USA \\ bartel@uvt.nl, \{campbell, fadi.deek\}@njit.edu
}

\begin{abstract}
This paper reports the findings of an experimental study of webbased negotiations among a group of distributed stakeholders involved in the design of a complex information system. Using a web-based communication system, the stakeholders had to reach agreement on a common set of software requirements taking into account their individual preferences as well as overall constraints of available time and budget. To support such complex negotiations, the objective of our study was to analyze the impact of providing structured task and explicit negotiation sequence support to the negotiating group with respect to their activity, conflict and satisfaction. Our results show that groups following a structured task are more active than groups lacking such structure. However, the absence of negotiation sequence and structured task support leads to greater satisfaction.
\end{abstract}

Keywords: distributed negotiation; software requirements; negotiation process support; group work; distributed group support systems.

\section{Introduction}

According to Weigand et al. [41], in a negotiation "there are two or more participants in a situation of some kind of interdependence, each having some individual goals which may be partially incompatible, and in some form of the negotiation process, alternatives are investigated, of which one is mutually agreed upon as the acceptable outcome of the process." In today's global economy, distances between businesses' physical locations, possibly located in different time zones, often leave business partners no alternative but to conduct distributed negotiations over the internet, typically supported by dedicated software [19]. The use of software to support communication among distributed groups has been studied since a long time. Hiltz and Turoff were among the first to conduct empirical research on the use of computer-mediated communication systems for distributed groups [20], and the use of Decision Support Systems for negotiators was proposed around the same time [35]. These pioneering developments later evolved into dedicated Negotiation Support Systems (NSS) to aid negotiators, for instance by generating alternatives based on knowledge of the negotiators' preferences and utility functions [22]. NSS often draw 
from models and approaches in multi-criteria decision making, preference analysis or game theory $[32,33,38]$.

Computer-mediated Communication (CMC) for software design teams has been investigated by Ocker and co-workers since the late 1990s [29, 30]. Ocker found that the creative task of deciding upon the initial specifications for the design of a software system can benefit from asynchronous CMC. Groups using CMC were found to be considerably more creative in their designs; the quality of the designs was also judged to be higher, though not significant [29]. In recent research on computer-mediated distributed software requirements engineering, Damian and co-workers studied the role of a facilitator in distributed group discussions. Faciliated meetings can help resolve disagreements among the group members, yet Damian found that " $a$ reduced richness of social behaviors in computer-mediated group settings made the groupfacilitation problematic" [9]. Clearly, due to the nature of mediated communication in asynchronous interaction, it is relatively more difficult to coordinate distributed groups, and as an alternative to human faciliation, specific coordination structures must be arranged to overcome these difficulties. Kim, Hiltz and Turoff have examined the effect of system restrictiveness of coordination structures in an asynchronous environment. Their study found that less restrictive coordination structures are more appropriate to support asynchronously interacting distributed groups [26].

We continue in this paper along the lines of the CMC research on the impact of structured interaction, and introduce two types of interaction structures: a structured negotiation task, and a structured negotiation sequence. The effect of these structures on group activity, the group's satisfaction with the negotiation process, and conflict within the negotiating group is the focus of our investigation. Activity, satisfaction and conflict are key variables in Group Support Systems (GSS) research (see [14] for a detailed survey on experimental research in GSS, with an exhaustive list of experimental variables). We in particular focus on negotiations that take place during the phase of system requirements definition. Negotiation is typically needed in this phase to address and resolve conflicting system requirements which have been articulated by the different stakeholders at, or prior to, the start of the system design process [23].

In the following section, Section 2, we provide a concise theoretical overview of negotiation research and negotiation models on which we base our experimental study. We also introduce electronic negotiation systems (ENS) which provide information, communication and decision support to the negotiating members of a distributed group. In Section 3, we present our research model and formulate our research hypotheses. The experiment we have designed is presented in detail in Section 4, and the results of our experiment are given in Section 5. These results are discussed in Section 6, followed by our conclusions and a discussion of the limitations of this study in Section 7 where we also suggest avenues for future research.

\section{Negotiation Research and Negotiation Support Systems}

\subsection{Negotiation Research}

Drawing from a wide area of disciplines, in particular cognitive psychology and behavioral decision research, negotiation researchers have come to view participants 
in a negotiation as interdependent decision makers whose behavior is a result of choices based on often conflicting judgments about the negotiation situation [1]. In negotiated decisions, conflict and interdependence are indeed two key aspects. Conflicts may arise during negotiations because of the participants having different goals, yet conflict can also result from participants having common goals but different ideas on how to achieve them [31]. Decision makers in a negotiation are also interdependent, as one participant reaching his or her objective is influenced by others agreeing to it, and vice versa. In case the negotiation involves multiple participants, conflict among the participants can add considerable complexity and confusion as each participant has only limited information or knowledge about the other participants' preferences [34, 39]. According to the process model of negotiations first proposed by Gulliver [17] and later expanded by Kersten [23], the phases and activities of multiple participants during negotiations can be described as follows:

- Search for arena and selection of the communication mode: reaching agreement on where the decision process will take place. This can be a face-to-face or virtual meeting space for synchronous or asynchronous exchange of information.

- Agenda setting: agreeing to the issues and, if possible, partial problem representation and categorization.

- Exploring the field: further problem specification and analysis where parties try to establish limits, formulate best alternatives, assess their opponents, and decide on initial negotiation strategies.

- Narrowing the differences and search for integration: through exchange of information, the participants learn of the limitations of others, their aspirations and objectives, and knowledge about efficient solutions and their outcomes.

- Search for agreement and improvements: identify critical issues and areas of disagreement, try to develop joint proposals to come up with a limited number of acceptable compromises.

\subsection{Distributed Group Support Systems and Electronic Negotiation Systems}

The use of computer technology may help overcome constraints that are experienced in either face-to-face (same time - same place) or distributed negotiation situations. Group support systems (GSS) are designed to support decision makers in complex negotiation tasks, and have been proven to benefit the exchange of information among participants $[11,28]$. It was found that groups interacting using a GSS exchanged about $50 \%$ more information than those interacting only verbally [11] or exchanged more unique, unshared information [34]. GSS structures or tools can be combined with basic communication support to enable decision making by groups distributed in space and time [7, 12] - a group support technology referred to as Distributed Group Support Systems (DGSS) [36]. Negotiation Support Systems (NSS) are GSS that specifically focus on negotiations and provide decision support to each negotiator [22, 27]. More advanced NSS feature group process structuring techniques, mediator support, and documentation of the negotiations [10, 15]. Electronic Negotiation Systems (ENS) in general employ the internet and computing technologies to support decision makers during negotiations, and have one or more of the following characteristics $[24,25]$ : 
- Supports decision and concession making;

- Suggests offers and agreements;

- Assesses and criticizes offers and counteroffers;

- Structures and organizes the process;

- Provides information and expertise;

- Facilitates and organizes communication;

- Aids agreement preparation, and

- Provides access to negotiation knowledge, experts, mediators, or facilitators.

ENS range from straightforward web-based communication systems to sophisticated intelligent systems actively contributing to the negotiation process by assessing what is being negotiated while interacting with participants and providing offer assessment and critiques of counteroffers.

\section{Distributed Software Requirements Negotiation: Research Model and Hypotheses}

\subsection{Software Requirements Negotiation Engineering}

Negotiating conflicting requirements is an important part of the requirements phase of the software engineering life cycle $[2,8,16]$. Many studies have found that clear, consistent, and traceable requirements result in more robust, maintainable information systems [5,6]. In order to provide this quality, consistency, and traceability, conflicts between users, analysts, and managers must be resolved during this important phase of software design and development [21]. Conflict in and of itself is not a negative activity at this stage of software development. Actually, conflict and its resolution at an early stage in the development process can have the result of saving both time and money further along in the development life cycle [18]. One of the most commonly known and studied approaches to resolving conflict and reaching agreement in requirements design is the spiral model proposed by Boehm and colleagues [3]. Boehm's spiral approach focuses on stakeholder collaboration and negotiation to achieve so-called 'win-win' software requirements where all stakeholders are winners in the negotiations. Boehm's model facilitates the uncovering and resolution of problems before they reach the implementation stage and therefore save time and money while at the same time enhancing software quality and reliability [4].

\subsection{Research Model and Hypotheses}

To support the negotiation process of groups whose members are distributed in space and time, an ENS can provide various levels of support to the negotiating group members. In this research, we focus on two basic types of support that the ENS can make available to negotiating parties: structured task and negotiation sequence support. We consider an ENS to provide structured task support when the ENS provides the negotiating group with clearly outlined specific steps on how to address their task, so that their discussions can proceed in a well-structured manner. In the absence of such a specific support within the ENS, we will consider the negotiation task as unstructured. Similarly, we consider the ENS to provide negotiation sequence 
support when the ENS provides the negotiating group with guidance on how to approach their negotiation, for instance by following the negotiation steps proposed by Gulliver and Kersten as described in Section 2.1 above. The objective of our research is to investigate how the presence or absence of structured negotiation task and negotiation sequence support in the ENS affects the activity during a distributed negotiation, as well as the satisfaction and conflict among participants.

Within GSS research, group effectiveness and productivity have often been measured in terms of number of ideas, alternatives or comments generated. Fjermestad and Hiltz identify not less than 167 productivity measures in their comprehensive review of about 200 experimental GSS studies published until 1998 [14]. Negotiation strategies, such as sequencing, can contribute to more collaboration and the convergence of different perspectives [3]. We therefore hypothesize:

H1a. Groups provided with negotiation sequence support will be more active compared to groups with no negotiation sequence support.

H1b. Groups provided with structured task support will be more active compared to groups with no structured task support.

Since structured task, as well as negotiation sequence support, provides guidance to the negotiating groups, we can hypothesize that their use in the ENS will reduce conflict in negotiating distributed groups:

H2a. Groups provided with negotiation sequence support will exhibit less conflict in their negotiations compared to groups without this support.

H2b. Groups provided with structured task support will exhibit less conflict in their negotiations compared to groups without this support.

Research on group decision making also investigates how satisfied groups are with the process to arrive at a decision. It has been shown that technology-supported groups can produce more democratic (individuals participating with equal value) or more fairly distributed decision-making processes $[12,40]$, which in turn leads to more satisfaction with the outcome. The more democratic the process, the more satisfying the group process and outcomes will be [13]. We therefore hypothesize:

H3a. Groups provided with negotiation sequence support will show more satisfaction with their negotiation process compared to groups with no negotiation sequence support.

H3b. Groups provided with structured task support will show more satisfaction with their negotiation process compared to groups with no structured task support.

\section{Research Methodology}

\subsection{Experimental Design - Independent Variables}

The independent variables in our experimental study are 'Structured Task' and 'Negotiation Sequence', leading to the 2 X 2 experimental design as shown in Table 1, which also lists the number of groups that were assigned to each experimental condition. Groups assigned in the 'structured task' condition are provided by the ENS with clearly outlined specific steps on how to approach their task. Groups assigned to 
the 'negotiation sequence' condition are aided through their negotiation by the ENS with guidelines according to the Gulliver and Kersten negotiation process [17, 23].

Table 1. Experimental design with number of groups and subjects per condition

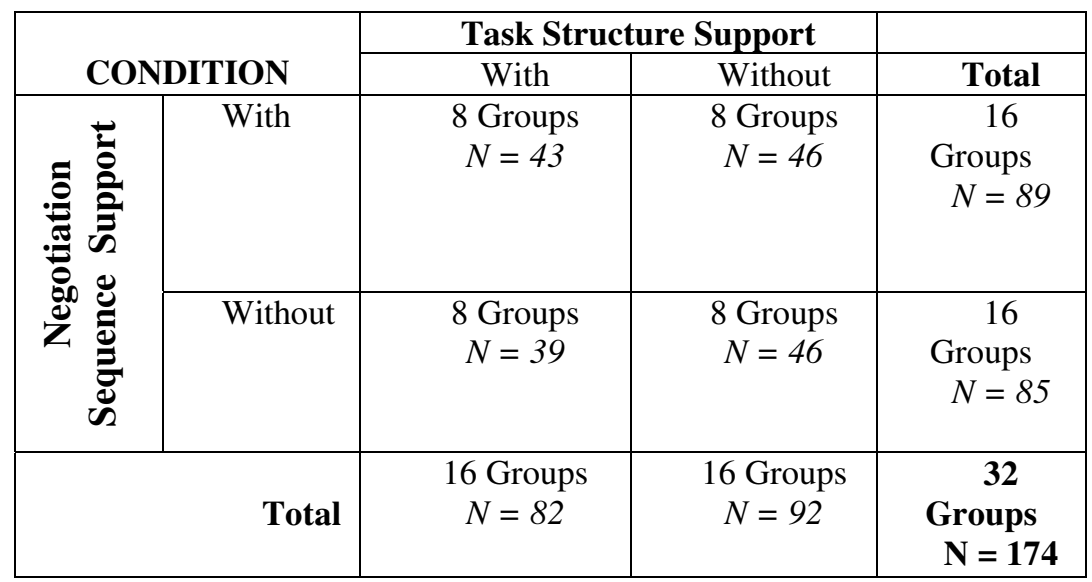

\subsection{Dependent Variables and Measures}

Three dependent variables are studied: Activity, Conflict, and Process Satisfaction. Conflict and Process Satisfaction are measured by a post-task questionnaire; the items used are listed in Table 2. All items are measured on a 7 point Likert-type scale with anchors from "Strongly disagree" to "Strongly agree". The questionnaire included items worded with proper negation and a shuffle of the items to reduce monotony of questions measuring the same construct. Activity is directly measured by the number of messages posted by the group.

Table 2. Conflict and Process Satisfaction question items used in the study

\begin{tabular}{|c|c|c|}
\hline $\begin{array}{l}\text { Dependent } \\
\text { variables }\end{array}$ & & Post-task questionnaire items \\
\hline \multirow[t]{2}{*}{ Conflict } & 1 & To what extent did the group experience conflict? \\
\hline & 2 & Did the group handle conflict effectively? \\
\hline \multirow{6}{*}{$\begin{array}{l}\text { Process } \\
\text { Satisfaction }\end{array}$} & 3 & How efficient would you describe your group's \\
\hline & & oblem solving process? \\
\hline & 4 & $\begin{array}{l}\text { How coordinated would you describe your group's } \\
\text { gotiation process? }\end{array}$ \\
\hline & 5 & $\begin{array}{l}\text { How fair would you describe your group's } \\
\text { gotiation process? }\end{array}$ \\
\hline & 6 & $\begin{array}{l}\text { How understandable would you describe your } \\
\text { oup's negotiation process? }\end{array}$ \\
\hline & 7 & $\begin{array}{l}\text { How satisfying would you describe your group's } \\
\text { gotiation process? }\end{array}$ \\
\hline
\end{tabular}




\subsection{Experimental Task}

The experimental task offers a hypothetical scenario in which a distributed group of stakeholders is asked to negotiate the design requirements for a new information system. The information system described in the task is an Emergency Response Information System (ERIS) that is to be developed for use in a (fictitious) US County, and the stakeholders are organizations in the County which would use or rely on the ERIS in case of an emergency [37]. Five distinct roles were presented in the task: law enforcement, fire containment, public works, public health, and state home/civil defense unit liaison. Each participant in the experiment was provided with a specific role description according to the stakeholder organization he or she represented, and a set of organization-specific requirements the organization would like to see implemented in the ERIS. Participants only knew their personal requirements and were not informed of the requirements of the other stakeholders. Some requirements were common to all stakeholders while others were unique to the respective organizations, yet either unique or common requirements could only be 'disclosed' through the negotiation. The task description indicated that state and local government funds had been obtained to actually implement the ERIS, a task which was to be carried out by an independent software firm. However, since the funding was insufficient to implement all and everyone's requirements, the stakeholders were asked to negotiate to agree on a subset of requirements that will go forward for implementation in ERIS and would satisfy, in some way, the stakeholders most pressing needs. The stakeholders were told that the software firm's Project Manager would join their negotiations, whose role was described as to supply costs and resources to the group, to chair the meetings, and to provide facilitation.

\subsection{Participants and Roles}

The subjects for this study were graduate students enrolled in Systems Analysis and Design and Software Engineering courses at the New Jersey Institute of Technology. Demographics were collected with an online background questionnaire. The distribution by major was Computer Science 36\%, Information Systems 15\%, Engineering $44 \%$, Management $2 \%$, and Other $3 \%$. The population included 51 females and 136 males. The education level of the students was $3.7 \%$ undergraduate seniors, $39 \%$ Information System Masters, 59\% Computer Science Masters, 1\% MBA, $2 \% \mathrm{PhD}$ students, and $13 \%$ Other. The ages of the participants ranged from under 23 to over 40 with the majority in the $23-30$ age range.

Subjects were randomly assigned to roles in groups of six, i.e., the five stakeholder roles and one Project Manager. The task was given to the students as part of their course work and they were graded individually on their participation. Initial participant training was completed in the classroom in a one-hour face-to-face training session. During this session the subjects were introduced to the domain topic and the general task to be completed, given a brief background of requirements engineering (this was covered in depth by their current or previous coursework), and introduced to the project roles and what was expected of them. 


\subsection{Electronic Negotiation Environment}

The commercially available WebBoard software (a product of Akiva Corporation) is used as the web-based collaboration environment in which the distributed groups are conducting their negotiations. Although WebBoard is not specifically designed as an ENS, and does not have any standard negotiation support tools built-in, it does allow for an easy configuration of its group communication structures (threaded discussion forums) so that negotiations can take place as threaded discussions. WebBoard has a proven track record within education and corporate environments to create virtual classrooms, for internal project collaboration, for establishing standards and best practices and for customer support applications. The WebBoard interface was customized for the experimental conditions to accommodate for the presence or absence of structured task and negotiation sequence support.

\subsection{Experimental Procedures}

The experiment was conducted over two consecutive semesters during the academic year 2003-2004 at the New Jersey Institute of Technology (NJIT). During the fall 2003 semester, a pilot study was run to test the technology, group roles and interactions, task, and experimental procedures. Based on the results of the pilot study, some changes were made for the formal experiment which was run with graduate students in spring 2004. In the formal experiment in spring 2004, there were 32 Groups with eight groups per condition. The total subject population participating at the start of the experiment was 192; as a result of drop-out during the time of the experiment, the total number of participants was 174. After completion of a training task, the subjects were allowed to start the negotiations which were to be conducted during five consecutive days. At the end of the negotiations, the groups had four days to complete and comment on the final report before uploading it to WebBoard. Upon completion of the negotiations, the subjects were directed to a post-task online questionnaire. The subjects were encouraged to complete the questionnaire as soon as possible after they finished negotiating or by the sixth day of the experiment at the latest. Upon completion of the experiment and submission of all required documentation, each instructor was given a suggested grade for participation of each subject. Subjects were invited to an online debriefing conference which detailed the experimental design, procedures, and a brief theoretical background for the research.

\section{Analysis of the Results}

\subsection{Negotiation Activity}

Negotiation Activity variable was measured directly by analyzing the WebBoard conferences in which the group conducted their discussions, and count the number of messages posted by the groups. 
Table 3. The ANOVA on messages posted

\begin{tabular}{lllll}
\hline Source & d.f. & MS & $\boldsymbol{F}$ & Significance \\
\hline $\begin{array}{l}\text { Negotiation } \\
\text { Sequence Support }\end{array}$ & 1 & 195.031 & .248 & .623 \\
$\quad \begin{array}{l}\text { Task Structure } \\
\text { Support }\end{array}$ & 1 & 4117.781 & 5.226 & $\mathbf{. 0 3 0}$ \\
$\quad$ Negotiation & & & & \\
$\begin{array}{l}\text { Sequence Support } \\
\text { Task }\end{array} \quad$ Structure & 1 & 1116.281 & 1.417 & .244 \\
$\begin{array}{l}\text { Support } \\
\text { Error }\end{array}$ & 28 & 787.942 & & \\
\hline
\end{tabular}

Of the 32 groups that participated in the experiment, 29 did reach consensus on the list of requirements to be implemented. 21 groups reached consensus within 6 days. 11 groups took six days, 5 groups took seven days and one group each took eight and nine days respectively. 4 groups that did not have a negotiation sequence or task structure reached agreement within five days, with the most groups reporting consensus within that time. A two-way between-groups analysis of variance was conducted to explore the impact of negotiation sequence and task structure support on the group activity as measured by the number of messages generated by each group. From Table 3, it follows that there was a statistically significant effect for task structure $(p=.030)$. Therefore, H1a is supported. The main effect for negotiation sequence $(p=.623)$ did not reach statistical significance. Therefore Hypotheses H1b is not supported. There was no statistically significant interaction effect $(p=.244)$.

\subsection{Conflict}

The Conflict variable was measured by the two different post-task questionnaire items given in Table 2. For both items, a one-way between-groups analysis of variance was conducted, the results of which are shown in Table 4. For the first item, "To what extent did the group experience conflict?", no statistical significant effect was found $(F=1.253, p=0.292)$. For the second item "Did the group handle conflict effectively?", a significant statistical effect was found $(F=$ 2.656, $p=0.05$ ) for the 'no negotiation sequence support' and 'no task structure support' conditions, meaning the groups in those conditions handled conflict the most effectively. The effect size, calculated using Eta Squared, was .04, and therefore the actual difference in means scores between the groups is quite small. Therefore, neither Hypothesis H2a (groups provided with negotiation sequence support will exhibit less conflict in their negotiations compared to groups without this support) nor Hypothesis $\mathbf{H 2 b}$ (groups provided with structured task support will exhibit less conflict in their negotiations compared to groups without this support) are supported. 
Table 4. ANOVA on Conflict

Conflict Measure 1: To what extent did the group experience conflict?

\begin{tabular}{lccccc}
\hline & $\begin{array}{c}\text { Sum of } \\
\text { Squares }\end{array}$ & df & $\begin{array}{c}\text { Mean } \\
\text { Square }\end{array}$ & F & Significance \\
\hline Between Groups & 10.342 & 3 & 3.447 & 1.253 & .292 \\
Within Groups & 467.566 & 170 & 2.750 & & \\
\hline
\end{tabular}

Conflict Measure 2: Did the group handle conflict effectively?

\begin{tabular}{lccccl}
\hline & $\begin{array}{c}\text { Sum of } \\
\text { Squares }\end{array}$ & df & $\begin{array}{c}\text { Mean } \\
\text { Square }\end{array}$ & F & Significance \\
\hline Between Groups & 14.335 & 3 & 4.778 & 2.656 & .050 \\
Within Groups & 305.854 & 170 & 1.799 & & \\
\hline
\end{tabular}

\subsection{Process Satisfaction}

The Process Satisfaction variable was measured in the post-task questionnaire by questions 3-7 as given in Table 2. Chronbach's alpha of the process satisfaction scale is 0.89 which indicates that this measure is valid. The questions are summed and averaged to achieve a scale measure for this variable. Significance was tested using a two-way Analysis of Variance test. There was no main effect for negotiation sequence $(p=.46)$. There was a statistically significant main effect for task structure $(p=.00)$. The interaction effect $(p=.13)$ did not reach statistical significance.

Table 5. ANOVA on process satisfaction

\begin{tabular}{lllll}
\hline Source & d.f. & MS & $\boldsymbol{F}$ & Significance \\
\hline $\begin{array}{l}\text { Negotiation } \\
\text { Sequence Support }\end{array}$ & 1 & 26.355 & .560 & .455 \\
$\quad \begin{array}{l}\text { Task Structure } \\
\begin{array}{l}\text { Support } \\
\quad \text { Negotiation }\end{array}\end{array}$ & 1 & 855.697 & 18.176 & $\mathbf{. 0 0 0}$ \\
$\begin{array}{l}\text { Sequence Support * } \\
\text { Task Structure Support } \\
\text { Error }\end{array}$ & 1 & 110.112 & 2.339 & .128 \\
\hline
\end{tabular}

The ANOVA results in Table 5 show that the Negotiation Sequence Support was not significant as a main effect $(F=0.560, p=0.455)$. Therefore, Hypothesis H3a (groups provided with negotiation sequence support will show more satisfaction with their negotiation process compared to groups with no negotiation sequence support) is not supported. Structured Task Support on the other hand is significant as a main effect $(F=18.17, p=0.000)$ : those groups that did not follow a task structure had significantly higher process satisfaction than those that did. This implies that Hypothesis H3b (groups provided with structured task support will show more satisfaction with their negotiation process compared to groups with no structured task 
support) also is not supported. There is no significant interaction effect between Negotiation Sequence Support and Structured Task Support $(F=2.339, p=0.128)$.

\section{Discussion}

The negotiation activity variable produced a significant effect for task structure. The groups using a task structure were significantly more active than those that were not provided with this structure. Negotiation sequence support however does not produce a significant effect, and the corresponding hypothesis is not supported. Also, there was no interaction effect for groups following a structured task and negotiation sequence. Using the task structure provided in the ENS may have helped the subjects focus on the task at hand and make the groups aware of all requirements available, leading to an increased communication activity.

The results of the items measuring the conflict experienced within the group show that the least conflict was in the groups that used no task structure and no negotiation sequence; this was a statistically significant finding. Therefore no conflict hypotheses were supported and our findings actually indicate the reverse of the experimental hypotheses for this variable. This may be explained by the fact that the lack of any support with respect to the task at hand and the negotiation process did allow the group members to communicate wherever and whenever they pleased within the electronic conference space. Since there was no guidance provided - no rules of the game - group members could not rely on 'objective' arguments to argue against this type of 'free' communication behavior. As such, the absence of structure may have lessened the pressure group members experience when participating in the negotiation. Conversely, it can be argued that the very presence of the structure and negotiation sequence support descriptions may have provided too much information for the students, leading to information overload.

The process satisfaction variable measured the negotiation and problem solving process as efficient, coordinated, fair, understandable, or satisfying. Satisfaction with the negotiation process of choosing a set of optimal requirements was found to be best when the groups did not follow either a negotiation sequence or structured task. Groups not following a structured task showed a significant result and felt the most satisfaction with their process, regardless of their negotiation support mode. Again, the absence of structure allowed the students to post freely, creating their own group process and communication structures in the WebBoard negotiation space. Subjects may prefer this type of communication mode and therefore may have felt less restricted in their group interactions. This perception may have been strengthened by most subjects' familiarity with the WebBoard software, which they have used for other purposes without task or negotiation support structures in place.

\section{Conclusions and Limitations}

Requirements negotiation has been well studied by several researchers, but to our knowledge this is the first study to address the negotiation of software requirements in an asynchronous and distributed communication mode. With global software 
engineering becoming the norm rather than the exception, interest in this area is increasing. Research interest has focused on the downstream phases of the software engineering process where workloads can more easily be partitioned and compartmentalized for distribution to different organizations or groups. The requirements engineering process has traditionally been conducted face-to-face. With the growth of global business and e-commerce, stakeholders are increasingly distributed, ensuring the contribution of all stakeholders is a crucial part of the requirements engineering process in order to obtain the most robust requirements for the proposed system. This research can contribute to encouraging and enabling distributed stakeholder groups to actively participate in the requirements process. The contribution of this research consists of a detailed analysis of two communication coordination mechanisms, the structured task and negotiation sequence. The results from our experiments were however less indicative than the authors had hoped for, which could be due to several limitations of this study.

Although there was an extensive pilot study prior to the formal experiment, several limitations still can be identified. Foremost perhaps, the experimental subjects were graduate students - a common experimental limitation that has affected several areas of the study. Most of the subjects were unfamiliar with the complex task domain of emergency response and therefore prior to participating, needed rather extensive training to participate in a meaningful manner. Subjects had to read and comprehend the roles and task; if these were not clear, it was difficult to negotiate from a position of strength and other stakeholders would be able to sway them more easily. In addition, many of the subjects had English as their second language, which also may have impacted their task and role comprehension. Another limitation of this study is the restrictive communication imposed on the participants, who could only communicate through the ENS (WebBoard). Nowadays, in most working environments, multiple modes of communication are concurrently used, such as chat or internet telephony. The single communication mode imposed by this experimental study may have been experienced as too rigid and restrictive by those subjects who had a more flexible experience in the work place.

These limitations also give us important directions for future research. The authors intend to conduct a follow-up experiment with professional emergency responders as subjects. Obviously, several restrictions regarding subject availability and ENS training and use have to be overcome. Preparations for this follow-up experiment are currently under way.

Acknowledgments. The first author's research is supported by the European Commission under the Sixth Framework Programme through a Marie Curie IntraEuropean Fellowship. We thank four anonymous referees for their helpful comments.

\section{References}

1. Bazerman, M., Carroll, J.S.: Negotiator cognition. Research in Organizational Behavior 9, 247-288 (1987)

2. Blackburn, J., Scudder, C., Van Wassenhove, L.: Concurrent software development. Communications of the ACM 43(11), 200-214 (2000) 
3. Boehm, B., Bose, P., Horowitz, E., Lee, M.J.: Software Requirements Negotiation and Renegotiation Aids: A Theory-W Based Spiral Approach. Communications of the ACM, pp. 243-253 ( 1995)

4. Boehm, B., Abi-Antoun, M., Port, D., Lynch, A.: Requirements Engineering, Expectations Management, and the Two Cultures. Center for Software Engineering, Technical Report, USC (1998)

5. Bray, I.K.: An Introduction to Requirements Engineering. Addison-Wesley, Essex, UK (2002)

6. Brooks, F.: No silver bullet: essence and accidents of software engineering. In: Kugler, H.J. (ed.) Information Processing, Elsevier Science Publishers, North-Holland (1986)

7. Bui, T., Jarke, M.: Communications requirements for group decision support systems. Journal of Management Information Systems 2(4), 8-20 (1986)

8. Conboy, K., Lang, M., Barry, C.: An investigation of the use of requirements prioritization in web-based information systems development. In: O'Toole et al. (eds.) Proceedings of 5th Irish Academy of Management Conference (2002)

9. Damian, D.E., Eberlein, A., Shaw, M.L.G., Gaines, B.R.: An Exploratory Study of Facilitation in Distributed Requirements Engineering. Requirements Engineering Journal 8(1) (2003)

10. Delaney, M.M., Foroughi, A., Perkins, W.C.: An empirical study of the efficacy of a computerized negotiation support system. Decision Support Systems 20, 185-197 (1997)

11. Dennis, A.R., Valacich, J.S., Connolly, T., Wynne, B.: Process structuring in electronic brainstorming. Information Systems Research 7(2), 268-277 (1996)

12. DeSanctis, G., Gallupe, R.B.: A foundation for the study of group decision support systems. Management Science 33(5), 589-609 (1987)

13. Dufner, D.: Effects of group support (listing and voting tools) and sequential procedures on group decision making using asynchronous computer conferences. Ph.D. Dissertation. Rutgers, The State University of New Jersey (1995)

14. Fjermestad, J., Hiltz, S.R.: An assessment of group support systems experimental research: methodology and results. Journal of Management Information Systems 15(3), 7-149 (1999)

15. Foroughi, A.: Minimizing negotiation process losses with computerized negotiation support systems. Journal of Applied Business Research 14(4), 15-26 (1996)

16. Grünbacher, P., Hofer, C.: Complementing XP with requirements negotiation. In: Proceedings of the 3rd International Conference on eXtreme Programming and Agile Processes in Software Engineering, pp. 105-108 (2002)

17. Gulliver, P.H.: Disputes and Negotiations: a Cross-Cultural Perspective. Academic Press, Orlando, Florida (1979)

18. Hall, T., Beecham, S., Rainer, A.: Requirements problems in twelve software companies: an empirical analysis. In: IEEE Proceedings of the Conference on Empirical Assessment in Software Engineering, pp.7-42 (2002)

19. Herbsleb, J.D, Moitra, D.: Global software development, IEEE Software, pp. 16-20 (March/June 2001)

20. Hiltz, S.R., Turoff, M.: The Network Nation: Human Communication via Computer. MIT Press, Cambridge (1993)

21. In, H., Roy, S.: Issues of visualized conflict resolution. In: Proceedings of the International Symposium on Requirements Engineering, Toronto, Canada, 10-15 (2001)

22. Jelassi, M.T., Foroughi, A.: Negotiation Support Systems: An Overview of Design Issues and Existing Software. Decision Support Systems 5, 167-181 (1989) 
23. Kersten, G.E.: Support for group decisions and negotiations, an overview. INTERNEG Working Paper, pp.332-246 (1997)

24. Kersten, G.E.: Modeling Distributive and Integrative Negotiations. Review and Revised Characterization. Group Decision and Negotiation 10(6), 493-514 (2001)

25. Kersten, G.E.: E-negotiation systems: Interaction of people and technologies to resolve conflicts. INTERNEG Research paper presented at UNESCAP Third Annual Forum on Online Dispute Resolution, Melbourne, Australia (2004)

26. Kim, Y., Hiltz, S.R., Turoff, M.: Coordination Structures and System Restrictiveness in Distributed Group Support Systems. Group Decision and Negotiation 11(5), 379-404 (2002)

27. Lim, L.H., Benbasat, I.: A theoretical perspective of negotiation support systems. Journal of Management Information Systems 9(3), 27-44 (1992)

28. Nunamaker, J.F., Dennis, A.R., Valacich, J.S., Vogel, D.R., George, J.F.: Electronic meeting systems to support group work. Communications of the ACM 34(7), 40-61 (1991)

29. Ocker, R., Fjermestad, J., Hiltz, S.R., Johnson, K.: Effects of Four Modes of Group Communication on the Outcomes of Software Requirements Determination. Journal of Management Information Systems 15(1), 99-118 (1998)

30. Ocker, R., Hiltz, S.R., Turoff, M., Fjermestad, J.: The effects of distributed group support and process structuring on requirements development teams: results on creativity and quality. Journal of Management Information Systems 12(3), 127-153 (1996)

31. Pruitt, D.G., Carnevale, P.J.: Negotiation in Social Conflict, Open University Press (1993)

32. Raiffa, H., Richardson, J.: Negotiation Analysis. In: The Science and Art of Collaborative Decision Making, Harvard University Press, Cambridge (2003)

33. Rosenschein, J.S., Zlotkin, G.: Rules of Encounter. The MIT Press, Cambridge (1994)

34. Rutkowski, A.-F., Van de Walle, B., Van Den Eede, G.: The effect of group support systems on the emergence of unique information in a risk management process: a field study. In: Proceedings of the 39th Hawaii International Conference on System Sciences HICSS39 (2006)

35. Sprague, R.H., Carlson, E.D.: Building effective decision support systems. Prentice-Hall, Englewood Cliffs (1982)

36. Turoff, M., Hiltz, S.R., Baghat, A.N.F., Rana, A.R.: Distributed group support systems. MIS Quarterly, pp. 399-417 (1993)

37. Turoff, M., Chumer, M., Van de Walle, B., Yao, X.: The design of emergency response information systems. Journal of Information Technology Theory and Application 5(4), $1-36$ (2004)

38. Van de Walle, B., Faratin, P.: Fuzzy preferences for multi-criteria negotiation. Position Paper for the American Association of Artificial Intelligence Fall, Symposium, Boston MA. Technical Report FS-01-03 (2001), pp. 116-119 (2001)

39. Van de Walle, B.: A relational analysis of decision makers' preferences. International Journal of Intelligent Systems 18, 775-791 (2003)

40. Watson, R.T.: A Study of Group Decision Support System Use in Three and Four-person Groups for a Preference Allocation Decision. Ph.D. Dissertation. University of Minnesota (1987)

41. Weigand, H., Schoop, M., de Moor, A., Dignum, F.: B2B Negotiation Support: The Need for a Communication Perspective. Group Decision and Negotiation 12, 3-29 (2003) 